\title{
Retained primitive reflexes: Perceptions of parents who have used Rhythmic Movement Training with their children
}

\author{
Tessa M Grigg, University of Canterbury, NZ \\ Wendy H Fox-Turnbull, University of Waikato, NZ \\ Ian G Culpan, University of Canterbury, NZ
}

\begin{abstract}
This article reports on a qualitative phenomenological research project that investigated the use of Rhythmic Movement Training (RMT) as an intervention for retained primitive reflexes. Participants were from seven families who each had a child between the ages of seven and 12 years. Through semi-structured interviews, parents described their reasons for seeking additional help with their child's development issues. They talked about finding RMT, using RMT within their family routine and their views on the costs and the benefits they experienced, both financial and time. While there has been a small amount of research into movement programmes targeting retained primitive reflexes, to-date there appears to have been no studies completed on RMT. The data collected described searches for help, the stress and frustrations associated with the search and the range of interventions these parents tried. The families in this research found that RMT was easy to use within their daily routine and that it was a cost-effective, low-impact intervention. The families noticed a range of benefits for children who had completed the movements. The findings provide encouraging evidence to proceed with further study that will investigate the academic, social and emotional development of children using RMT.
\end{abstract}

Keywords - Children, learning and behavioural intervention, primitive reflexes, qualitative study, retained primitive reflexes.

\section{INTRODUCTION}

Primitive (also known as infant, or primary) reflexes play a significant role in the development of a child (Damasceno et al., 2005). There are estimates that $48 \%$ of primary school-aged children have some level of primitive reflexes present (Goddard-Blythe, 2005) and research (McPhillips and JordanBlack, 2007b, McPhillips and Sheehy, 2004, Konicarova and Bob, 2012) showing links between retained reflexes and cognitive and behavioural outcomes for children make this an issue that needs consideration. The research discussed in this article gathered information from parents who had used a reflex integration programme (Rhythmic Movement Training - RMT) with their children to address behavioural and developmental issues.

Why and how parents choose interventions and considerations of family routine particularly relating to RMT were aspects covered in this research.

Rhythmic Movement Training (RMT) (Blomberg and Dempsey, 2011) is a programme of exercises developed to aid the integration of retained primitive reflexes. The exercises require little if any equipment and can be completed at home. Retained primitive reflexes can result in a range of developmental and behavioural issues relating to maturity, such as poor reading skills, poor balance and co-ordination, hyper-sensitivity, poor memory and attention skills. RMT was developed with an aim of improving such skills by allowing the integration of the primitive reflexes no longer needed by the child.

Primitive reflexes develop before birth, are activated through the birthing process and are critical in the child's early months. These involuntary reactions, originating in the brainstem, are fundamental to the chiild's future development (Capute, 1982, Desorbay, 2013, Goddard, 1996, Sassé, 
2009). Examples of reflexes that have attracted empirical research include the Moro reflex that lets the caregiver know the baby is frightened and has been associated with ADHD (Konicarova and Bob, 2012); the Spinal Galant reflex which constantly empties the new baby's immature bladder and later can contribute to hyperactivity and distractibility (Konicarova and Bob, 2012); and the Asymmetric Tonic Neck Reflex (ATNR) which initially controls limbs and later controls hand-eye coordination, has attracted significant research due to its connection with reading achievement and classroom based skills (Goddard-Blythe, 2005, Goddard-Blythe, 2012, Jordan-Black, 2005, McPhillips, 2014, McPhillips and Jordan-Black, 2007b, McPhillips and Jordan-Black, 2007a, Piek et al., 2008). The reflexes are inhibited and integrated (disappear) as the child matures, and this process allows movement and intellect to be controlled through postural reflexes and cognition rather than primitive reflex.

Maternal, birth and environmental stress have been implicated as interrupters of reflex integration (Goddard-Blythe, 2000, Holley, 2010, Blomberg and Dempsey, 2011, Hsieh et al., 2011). A retained Spinal Galant reflex can contribute to the bedwetting of a child beyond five years of age while a retained Moro reflex can cause balance and co-ordination issues (Berne, 2006). Research by McPhillips and Jordan-Black(McPhillips and Jordan-Black, 2007b) concluded that that there may be a link between retained reflexes and educational skill delays.

\section{METHODOLOGY AND RESEARCH DESIGN}

\section{Research questions}

The over-riding research question for this study was:

What are the experiences of parents who have used Rhythmic Movement Training (RMT) with their child?

The research question was answered using the following supplementary questions:

- What path led the family to RMT?

- How did completing the RMT exercises affect the household routine?

- What changes were noticed in the child's development while they were using RMT?

- Did the actual investment of resources (time and financial) match the anticipated input into RMT?

- Did the effect of RMT match the input of resources?

The research questions were approached using a qualitative research method. As an investigative methodology, phenomenology sits well with the complexities of parental experiences of the phenomenon of RMT (Snape and Spencer, 2003).

\section{Participant selection}

Purposeful sampling was used (Creswell, 2013) and seven client families from four RMT practitioners in New Zealand were selected to enhance the trustworthiness of the data. To enhance validity of the information gathered, two adults in each family were interviewed independently about the programme. In all seven families, it was the father and mother who were interviewed.

Crystallisation (Richardson and Adams St Pierre, 2008) was the process of validation used. Children were not interviewed because the aim of the study was to gather parents' perspectives. All names used in the findings are pseudonyms. One child, aged seven to 12 years, within each participant family had used RMT. The purpose in limiting the age of the children was firstly to give parents an opportunity to use school reports to support any comments they made about their child's development. Secondly, 
experiences of parents with children in this age range would be useful for further study investigating the efficacy of RMT with school-aged children; and thirdly, previous studies of reflex integration programmes have used children within this age range (Brown, 2010, Goddard-Blythe, 2012, McPhillips and Sheehy, 2004).

The parents in this study chose to use RMT as an intervention for a formally or informally identified developmental or behavioural need in their child. RMT exercises had been used by all of the families for at least six months, ensuring that their comments related to an extended period of RMT use. Parental comments have been identified as having inceased usefulness if the particition in the programme being researched has been for an extended period (Koh et al., 2010).

\section{Procedure - Data Collection}

Semi-formal interviews were arranged with participants and each lasted between nine (father's interviews were nine to 15 minutes) and 68 minutes (mother interviews were between 33 and 68 minutes). Parents were interviewed in a setting of their choice, with all choosing their home. 14 interviews provided the data for this research, 10 were face-to-face interviews and four were conducted over internet connections such as phone or Skype. Each interview involved a three-step process. The interview had a series of starter questions for each step (Creswell, 2013). Step one focused on the child and the parent's perceptions of the developmental needs of that child; e.g. 'Can you describe your child's educational journey so far?' 'What are your child's main challenges?' The second step focused on the parent's perceptions of the RMT programme and the third step focused on the parent's evaluation of the RMT programme in relation to cost, effectiveness and perceived benefits.

Ethics approval for this research was given by the University of Canterbury's Educational Research Human Ethics Committee (ERHEC) and consent from children and parents was obtained (Neill, 2005).

\section{Data analysis}

A thematic approach to data analysis was used. To ensure in-depth knowledge of the interview material all interviews were transcribed by the researcher. The transcriptions were then coded using NVivo software. Comments that related to a similar topic were grouped together; factors that led the family to seek interventions, the way they found RMT, fitting RMT into their routines, changes they noticed in their child or family life, their assessments of the cost/benefit of using RMT and comments about their RMT practitioner. This coded information was assessed and a range of themes emerged. Through a grouping process the final themes (Bogdan and Biklen, 2007, Creswell, 2013) as listed in the section below were used to convey the perceptions of the 14 participants.

\section{FINDINGS AND DISCUSSION}

The findings and discussion are considered within the six themes.

- Theme 1 - 'Please help me'; related to the parent asking for help and then the associated frustrations encountered when the 'help' was slow to arrive.

- Theme 2 - Self responsibility; related to the approach the parents took in an attempt to help the development of their child.

- Theme 3 - Creativity and RMT; related to the ways that parents used RMT

- Theme 4 - Relationships and RMT; related to the positive relationship outcomes parents noticed.

- Theme 5 - RMT made a difference; related to the skill development that parents observed in their children. 
- Theme 6 - Low impact, cost effective intervention; related to the investments (time and money) made by parents in relation to the perceived outcomes.

Theme 1 "Please help me!

Theme 1 found that all participants knew early on that their child was developing additional challenges not observed in other children. Parents observed delays in speech, physical skills and social skills in their pre-school children. These conclusions were obtained through interactions with siblings and/or noticing different skill sets in similar aged children in pre-school settings. Three families had their child's development assessed professionally at an early age, but for others it was just a 'feeling' they had. They believed that their child's development was not progressing normally and help was needed. The concerns expressed by a parent are important and they often have insights as to their child's needs that outsiders may not (Koh et al., 2010, Paige-Smith and Rix, 2006). For the seven families in this research their 'feeling' proved correct and in five of the families, the children's developmental challenges required significant levels of intervention. Early intervention is more effective in relation to later outcomes (Tomasello et al., 2010, Williams and Holmes, 2004), as is support for parents in obtaining the necessary help. In this research parents felt that support from child development professionals was slow to commence and interventions difficult to access. This led them to look for alternatives.

Stress and frustration was a sub-theme within the first theme. Bronfenbrenner's bio-ecological system theory places the child at the centre of a range of systems (Bronfenbrenner, 1997, Bronfenbrenner, 2005). He believes that these 'systems' have a significant effect on the development of the child. In all the families interviewed the 'systems' as identified by Bronfenbrenner were complicated, which was a source of stress and frustration for them. From this research two examples emerged; families home-schooling their child because they believed the school environment would increase their child's stress, and a family who paid for a teacher aide. These parents adjusted the 'system' to better meet the needs of their children.

Parents also identified the stress of needing to fund their child's interventions. Additional time and financial pressures were highlighted, with five mothers and one father talking about applying for funding. In four of these cases their applications were unsuccessful.

We tried to get funding for schooling through the Ongoing Resource (ORs) funding process,

but we were declined on several occasions (Stu).

Stu's child was diagnosed with severe dyspraxia. The parents of all the children felt that their only choice was to personally fund the interventions their child needed.

Within the seven families in this research, frustration was evident in their responses. Tomasello, Manning and Dulmas (2010) found that Family Centred Care was successful in minimizing stress and frustration for families through enhancing self-determination in relation to their child's care. However, four mothers in this research noted a perceived lack of understanding from health professionals about skills and behaviour that fell outside the norms. There was also a strong feeling that as mothers they were not listened to when they expressed concern about their child.

I was told "Oh babies are all different in different things and have different developments."

And I thought, I don't believe you, but anyway. I knew something wasn't right (Bella).

Theme 2 -Self responsibility; related to the approach the parents took in an attempt to help the development of their child

Theme 2 related to self-responsibility and was centered on the parents' need to take charge of interventions for their children. This was a common theme for all families in this research. It was 
noted that all families were two-parent families with at least one parent working full-time. They were all able to budget for the interventions they chose, although some programmes were discarded due to the high cost. For low income or single parent families, options may limited.

Two parents commented directly that 'the system' was not going to meet their child's needs. They felt they needed to take charge and actively seek ways to help their children. Four families stated that 'the system' had failed them. They described the long waiting time to see professionals and this had prompted them to take immediate action.

We found that the system was very ineffective. We started actually paying for

intervention, we got an OT [Occupational Therapist], and we started paying for a

speech therapist, all those kinds of things (Gemma).

This feeling is supported by Williams' (2005) research, where identification of a child's developmental issues was not established until they were at school, and Hendrickson et al.'s (2000) research that found parents had been prevented from accessing early intervention. These studies did not assess parental action in relation to their child's intervention needs, but they do highlight the problem parents can experience.

The support given to parents by their RMT Practitioner was mentioned in four interviews. A study completed by Paige-Smith and Rix (2006) found that parental satisfaction was an essential part in intervention programme success. Several parents in this research noted the high value they placed on the support their practitioner provided. This was a factor in them continuing with RMT.

All the families in this research had utilized programmes that were offered at school, as well as osteopaths and physiotherapists, occupational, speech, vision and nutritional therapists. Community-based programmes including Kiwi GymbaROO, Scouts and music classes were also mentioned. It appeared that these parents were willing to try many things and understood that development is multifaceted. RMT was found through word of mouth for six of the families, and for one family through a book.

\section{Theme 3 - Creativity and RMT; related to the ways that parents used RMT}

Theme 3 focused on creativity and the use of RMT. The RMT exercises have been developed in such a way that families can employ a range of creative strategies to engage children and ensure their completion. All participants appreciated this element of the programme and commented on it. Examples included the incorporation of RMT in dance moves or renaming the exercises as the 'jiggles'. Several parents commented on the flexibility with which the exercises could be fitted into family life; it "slotted in" to what they were already doing. If the programme is to be used in a classroom setting these comments are significant. They also highlight the need for further research. Literature relating to how parents fit a reflex integration programme into their family routine is sparse. While there are current reliable classroom-based studies, their use in the home setting has not been investigated. The Reynolds et al. (2003) study had children completing an exercise programme at home, but controversy surrounding this study leaves some doubt over the reliability of the results. Critics highlighted the flaws in the study's design and the reporting of inflated results (Bishop, 2008, McPhillips, 2003, Singleton and Stuart, 2003).

All the mothers and four fathers talked about the ease with which they completed the exercises with their child. Seven parents compared RMT to other interventions, and in ranking them by their ease of use, RMT was described by parents as one of the "easy ones". "Transportability" was a description used by one mother and this sentiment was repeated by others. The absence of specialized equipment or setting appealed to the parents. This would also be significant for a classroom-teacher if they were to integrate RMT into their routine. 
Theme 4-Relationships and RMT; related to the positive relationship outcomes parents noticed

Theme 4 related to relationships and RMT and the part RMT played in building relationships. The rapport between parent and child develops the microsystem (Bronfenbrenner, 1997) within which they live (Cicchetti et al., 2000). Engaging a child with skill challenges can be difficult for parents but it is understood that parental interactions impact children's development (Blacher et al., 2013) and developing opportunities to have positive interactions is important. Blacher et al. (2013) found that it was easier for parents to have positive interactions in unstructured activities (e.g. playing at the pool) where there was less need to intervene, rather than structured activities (e.g. completing reading at home) where intervention need is higher. Six parents in this research observed that RMT (a structured activity) provided an opportunity for more positive interactions with their children. One mother commented on spending much of the day diverting and correcting her child, whereas with RMT, while it was a structured activity, she was able to make it an "easy, fun time".

It was an opportunity to be with your child physically, actually making physical contact with the child to model the movements... And that the movements were very relaxing and to watch particularly Thorin go from what we called a nonyellow banana, to being more straight and relaxed (Sarah).

Developing strong attachments has been shown to be important for children as they develop (Pace and Zavattini, 2011) and if RMT plays a positive role in that process then that in itself is a beneficial outcome.

Parents also described the RMT practioners positive influennces on their whole family . Ongoing support and information from the practitioner and the high level of patience shown towards their child were commented on. Decriptions included "Godsend" and "I don't know what we would have done without [RMT Practitioner]" as families talked about their relationship with their RMT practitioner. Paige-Smith and Rix (2006) showed that intervention outcomes are improved when parents are supported. The RMT practitioners used by families in this research appear to have embraced this aspect of their work. Parents decsribed their child's enjoyment of time spent with their RMT Practitioner. They also noted that their child participated fully during the sessions.

I mean, [RMT Practitioner], I can never tell you everything that she has done cos she has done so much for him. She has had patience where I haven't and she certainly tells me when I need to step back, which is great, (Laughs) no I mean, as I say, it, if it wasn't for [RMT Practitioner] he wouldn't be where he is now. And I really mean that (Bella).

Theme 5 - RMT made a difference; related to the skill development that parents observed in their children.

Theme 5 related to the parent's comments about the differences they noticed in their children while using RMT. Neurologically based exercises, RMT focuses on brain maturation after the baby's reflex-based beginnings (Blomberg and Dempsey, 2011). The participant parents observed a range of skill development. Research by Diamond (2000, Diamond, 2007) found an interrelatedness between genes, environmental factors and development. She found connections between, social, cultural and physical environments and the interaction with an individuals genes. A broad approach to intervention, including all aspects of development was found to be of most benefit for children. She 
recommended further research be undertaken with relative importance placed on the all aspects of development, and a particular emphasis on movement-based activities. Parents in this research noticed a range of changes in their children, from social, emotioal and physical skill increases, to academic skill development. These observations and the movement-based RMT exercises have synergies with Diamond's work.

Well he sort of evened out a bit more than what he was and he is more able to do two or three things at a time. So, he is more comfortable and aware of what is body is actually doing which is one of the benefits (Lizzie).

Improvements in emotional well-being of the children was noticed while RMT was being used. Parents commented that children enjoyed the exercises and that the child was often noticeably calmer after completing the exercises. Explanations for these outcomes include; the rhythmic nature of the exercise which has been reported to have a calming effect on some children (Blomberg and Dempsey, 2011), the child may enjoy the one-on-one interaction with the parent or practitioner and they may like the physical nature of the exercise. The ability to adapt the exercises to accomodate the child's situation, and the simplistic nature of the activity enabled families to find positive options for completing them. Four mothers noted that other programmes they were engaged in appeared to be supported by RMT. For one family, the first big development they noticed was the child's ability to negotiate a large space. He had always needed to stay close to a wall when moving to another activity, but after he had begun RMT he was able to move directly from one activity to another. The child's anxiety relating to large spaces was reduced by this seemingly small change, and was followed by significant changes in his ability to function at his kindergarten.

Research showing physical skill improvements when completing reflex integration programmes are limited. However as already mentioned, Diamond (2007) believes that all development is inter-related. Parents in this research talked about improved skills associated with bike riding, ball skills and swimming. From their perspective, these were highly measurable skills. The activities became noticeably easier for the children during the time they were engaged with RMT. Brown's study (2010) researched the influence of a reflex integration programme and fine motor skill development. She found a positive correlation when the programme was used and this resonated with comments made by participants in this research. Improved writing skills, especially neater handwriting, was commented on by parents and it was noted that the development accelerated when the child was using RMT.

Research on two reflex integration-based programmes; Institute for Neuro-Physiological Psychology (INPP) and Primary Movement show improvements in reading ability during and after their use (Goddard-Blythe, 2005, McPhillips and Jordan-Black, 2007b). Reading skills were perceived by parents as an issue for the children in this research. Five parents commented on reading skill progress and maths improvements they noticed while their children were engaged in the RMT programme. This aligns with McPhillips and Sheehy's research (2004) that identified a prevalence of persistent primitive reflexes and motor skill deficits in students with reading challenges. GoddardBlythe (2005) concluded that using the Institute of Neuro- Physiological Psychology (INPP) programme with achadmically underachieving children who had elevated reflex retention successfully improved their outcomes. In Goddard-Blythe's (2005) meta-analysis there were significant improvements in reading and spelling after children had completed the INPP reflex integration programme. In this research, parental perspectives of RMT were in focus rather than academic outcomes based on standardized testing. However, while using RMT, improved reading was noticed by seven parents. 
Several families highlighted social skill challenges for their children, particularly the ability to integrate well in social situations. Siblings highlighted the lack of social development for five of the participants. Taylor et al. (2004) found that a significant proportion of boys with high levels of impulsive, emotional and problematic behaviours had retained reflexes. The parents in this research support these findings. They described behavioural challenges and social immaturity in their children, although once the children were using RMT these issues began to resolve. Parents noticed that their children increased their engagement with peers, with activities such as Scout Camps being willingly undertaken.

Theme 6 - Low impact, cost effective intervention; related to the investments (time and money) made by parents in relation to the perceived outcomes

Theme 6 discussed cost and resource impacts of the intervention. RMT was well liked as an intervention. All families commented that it was cost-effective and easy to complete.

The children both enjoyed the RMT therapy a lot more [than other therapies they

had done]. It didn't kind of upset them in any way (Gandalf).

However, it must be remembered that these families had all used RMT for at least six months. People who found RMT difficult to implement, or did not like the programme were not included in the research. Koh et al. (2010) state that parents who have used a programme for an extended period provide more reliable information than those who have experienced a programme for a shorter time. The methodology in this research acknowledges this.

A range of self-funded interventions were used by all of the families. They all commented that when comparing programmes, RMT was definitely cost-effective. None of the families had used an alternative reflex based programme such as the Institute of Neuro-Physiological Psychology (INPP) (Goddard, 1996), but one family was aware of both the financial and time costs associated with that particular programme. One mother commented that her child's ADHD behaviours would have probably resulted in the use of Ritalin and she believed that RMT had helped keep her child drug-free. This research is not testing the efficacy of RMT, but investigation of this claim would be interesting. Could children with retained reflexes and mild ADHD behaviours remain drug-free by using reflex integration exercises?

\section{IMPLICATIONS AND CONCLUSION}

\section{Summary}

The path this group of participant parents travelled to establish and access additional help for their children with behavioural and developmental needs had many challenges. Confusing advice, along with the difficulty in convincing medical and educational professionals of a developmental problem with their child, was frustrating for families. In their attempt to achieve the best outcomes for these children, families participated in a range of intervention programmes. Parents play an essential part in any intervention for a child and it has been shown that when they are engaged in the intervention process the outcomes improve (Koh et al., 2010).

Parents stated that they found RMT through word-of-mouth. For all of these parents, assuming responsibility for their child's challenges included a self-funding approach to interventions. They also noted that that they were fortunate to be in a financial position to fund the additional assistance required for their children. 
The parents in this research found RMT easy to use within the daily routine and high levels of child compliance were achieved through creative activites. RMT was described as a cost-effective, low-impact intervention by the parents. They noticed their children gained a range of cognitive, physical, and social skills while the RMT exercises were being used. Improvements in mother/child relationships were also noticed.

\section{Strengths and limitations of this research}

This research has comprehensively examined the perceptions and experiences of seven families (14 parents) in relation to their children's developmental needs, and their experiences with RMT. To-date the focus of empirical research has not been on the perceptions of parents and primitive reflex integration programmes although it has been concluded that parent perceptions are an important consideration when researching intervention programmes for children (Koh et al., 2010). This is the strength of this research. Previous reflex integration researchers have limited their studies to one or two reflexes (Goddard-Blythe, 2005, Brown, 2010, McPhillips and Jordan-Black, 2007b, McPhillips and Sheehy, 2004). However, in this research, reflex integration or the particular reflex present were not the focus. The final strength of this research is that it was home-based rather than classroombased. Different perspectives have be gained and challenges faced by families carrying out programmes at home have been explored.

While this research provides a range of useful information, there are some limitations. The number of participants is relatively small, as is common with qualitative research (Creswell, 2013). The behavioural challenges and the developmental range of the children in the seven families who had used RMT could be identified as a limitation. The differing challenges of the children does not allow for detailed comparrisons of similar developmental issues.

The limited sample of participants does not provide a representative sample of New Zealand families. The seven families were two parent-families with one parent in full-time employment and the second parent in part-time employment or not in any form of paid employment. There were no single-parent families. Low income families are likely to be excluded from the programme due the the self-funding required. From a cultural diversity perspective, there was one Australian mother and the rest of the families were of New Zealand-European descent. This is not representative of the cultural mix within New Zealand communities. The reason for this was not obvious and was not explored.

\section{Areas for further RMT research}

Further opportunities for investigation are highlighted by this research. Parents found that RMT was easy to use within the home. However, the next question is; can RMT be successfully implemented in a classroom setting and are there positive results in relation to skill development? Cost effectiveness, transportablility, requirements of little or no equipment and the small amount of time taken are positive aspects of RMT. Teachers with limited resources (funding or time) to complete programmes within a full curriculum may be attracted to this programme. Significant areas for further research include; does RMT actually make the changes for children the way the parents' perceptions indicate? To date there have been studies that have assessed other reflex integration programmes (Goddard-Blythe, 2005, Brown, 2010, McPhillips and Jordan-Black, 2007b), but RMT has not attracted any evidenced-based research. The findings of this research indicate that this might be the next logical step to take.

\section{Recommendations}

This research progresses further considerations for parents, teachers, occupational therapists, behavioural therapists and policy makers and it is not just about RMT.

1: Parents needing easier access to a wider range of assistance and interventions to improve educational and behavioural outcomes was highlighted. Offering discretionary funding to parents of 
children with challenges would give them opportunities to choose how that money is spent on interventions they could access.

2: A second point is the need for improved education for teachers (and medical professionals) in the area of child development, with a focus on early intervention for developmental challenges.

Recognition of early signs of developmental delay in children and knowing how to respond appeared to be lacking for this group of parents. Teachers and doctors are often the first point of contact for a parent and they are well placed give guidance to parents regarding specialist help. Teacher educators are in the best position to educate teachers in the range of developmental challenges, the range of specialists available and the appropriate action that can be taken with early intervention being the goal.

3: The final recommendation is to systematically research student achievement and behavioural outcomes when RMT is being used. Parents talked about perceived improvements, but can these be measured? The parents said that the RMT programme was easy to use within the home setting but could this programme be successfully used in the classroom or early childhood setting?

Conclusion

Discussion regarding the impact retained primitive reflexes have on educational and behavioural outcomes for children needs to continue. It is possible that retained reflexes underlie some of the challenges faced by some children. This group of parents used RMT as one of the interventions they tried and the simplicity and cost effectiveness of the exercises could make them available to a wide range of children. While presenting issues need attending to, addressing retained primitive reflexes as a cause could reduce time and cost spent in remediation, with improved outcomes for parents and educational institutions.

Published in Journal of Child Health Care. March 2018

Corresponding Author:

Tessa Grigg

College of Education, Health and Human Development

University of Canterbury

Christchurch, New Zealand

e-mail: tessa.grigg@pg.canterbury.ac.nz

\section{REFERENCES}

BERNE, S. A. 2006. The primitive reflexes: Considerations in the infant. Optometry \& Vision Development, 37, 139-145.

BISHOP, D. V. M. 2008. Letters to the Editor. Wiley-Blackwell.

BLACHER, J., BAKER, B. \& KALADJIAN, A. 2013. Syndrome specificity and mother-child interactions: Examining positive and negative parenting across contexts and time. Journal of Autism \& Developmental Disorders, 43, 761-774 14p.

BLOMBERG, H. \& DEMPSEY, M. 2011. Movements that heal, Queensland, Book Pal.

BOGDAN, R. C. \& BIKLEN, S. K. 2007. Qualitative research for education. An introduction to theories and methods, Boston MA, Pearson Education Inc and Allyn \& Bacon.

BRONFENBRENNER, U. 1997. Ecological systems theory. In: VASTA, R. (ed.) Six theories of child development: Revised formulations and current issues - New ed. 2nd ed. London: Jessica Kingsley Publishers Ltd. 
BRONFENBRENNER, U. 2005. On the nature of bioecological theory and research. In: BRONFENBRENNER, U. (ed.) Making human beings human : Bioecological perspectives on human development. Thousand Oaks, CA: Sage Publications.

BROWN, C. G. 2010. Improving fine motor skills in young children: An intervention study. Educational Psychology in Practice, 269- 279.

CAPUTE, A. J. 1982. Motor functions: Associated primitive reflex profiles. Developmental Medicine \& Child Neurology, 24, 662-669.

CICCHETTI, D., TOTH, S. L. \& MAUGHAN, A. 2000. An ecological-transactional model of child maltreatment. In: SAMEROFF, A. J., LEWIS, M. \& MILLER, S. M. (eds.) Handbook of developmental psychopathology. 2nd ed. New York, NY: Kluwer Academic/ Plenum Publishers.

CRESWELL, J. W. 2013. Qualitative inquiry \& research design - Choosing among five approaches, London, SAGE Publications Inc.

DAMASCENO, A., DELICIO, A. M., MAZO, D. F. C., ZULLO, J. F. D., SCHERER, P., NG, R. T. Y. \& DAMASCENO, B. P. 2005. Primitive reflexes and cognitive function. Arquivos de Neuro-Psiquiatria, 63, 577-582.

DESORBAY, T. 2013. A neuro-developmental approach to specific learning difficulties. International Journal of Nutrition, Pharmacology, Neurological Diseases, 3, 1-2.

DIAMOND, A. 2000. Close interrelation of motor development and cognitive development and of the cerebellum and prefrontal cortex. Child Development, 71, 44.

DIAMOND, A. 2007. Interrelated and interdependent. Developmental Science, 10, 152-158.

GODDARD-BLYTHE, S. 2000. Early learning in the balance: Priming the first ABC. Support for Learning, 15(4), $154-158$.

GODDARD-BLYTHE, S. 2005. Releasing educational potential through movement: A summary of individual studies carried out using the INPP Test Battery and Developmental Exercise Programme for use in schools with children with special needs. Child Care in Practice, 11, 415-432.

GODDARD-BLYTHE, S. 2012. Assessing neuromotor readiness for learning: The INPP developmental screening test and school intervention programme, West Sussex, John Wiley and Sons Ltd.

GODDARD, S. 1996. A teacher's window into the child's mind, Eugene, OR, Fern Ridge Press.

HENDRICKSON, S., BALDWIN, J. H. \& ALLRED, K. W. 2000. Factors perceived by mothers as preventing families from obtaining early intervention services for their children with special needs. Children's Health Care, 29, 1-17 17p.

HOLLEY, P. A. 2010. Why do some learn more easily than others? What physical factors influence effective learning? Master of Education, University of Melbourne.

HSIEH, C.-J., JENG, S.-F., WU, K.-Y., SU, Y.-N., LIAO, H.-F., HSIEH, W.-S. \& CHEN, P.-C. 2011. GSTM1 modifies the effect of maternal exposure to environmental tobacco smoke on neonatal primitive reflexes. Nicotine \& Tobacco Research, 13, 1114-1122.

JORDAN-BLACK, J. 2005. The effects of the Primary Movement programme on the academic performance of children attending ordinary primary school. Journal of Research in Special Educational Needs, 5, 101-111.

KOH, M.-S., SHIN, S. \& YEO, M.-H. 2010. The Learning Program for the Development of Autistic Children (LPDAC): Parents' perspectives on the treatment outcomes. Journal of the International Association of Special Education, 11, 92-100. 
KONICAROVA, J. \& BOB, P. 2012. Retained primitive reflexes and ADHD in children. Activitas Nervosa Superior, 54, 134-137.

MCPHILLIPS, M. 2003. A commentary on an article published in the February 2003 edition of 'Dyslexia', 'evaluation of an exercise-based treatment for children with reading difficulties' (Reynolds, Nicolson, and Hambly). Dyslexia (10769242), 9, 161-163.

MCPHILLIPS, M. 2014. Primary Movement [Online]. Belfast: Primary Movement. Available: http://primarymovement.org/about/index.html [Accessed].

MCPHILLIPS, M. \& JORDAN-BLACK, J. 2007a. The effect of social disadvantage on motor development in young children: A comparative study. Journal of Child Psychology \& Psychiatry, 48, 1214-1222.

MCPHILLIPS, M. \& JORDAN-BLACK, J. 2007b. Primary reflex persistence in children with reading difficulties (dyslexia): A cross-sectional study. Neuropsychologia, 45, 748-754.

MCPHILLIPS, M. \& SHEEHY, N. 2004. Prevalence of persistent primary reflexes and motor problems in children with reading difficulties. Dyslexia, 10, 316-338.

NEILL, S. J. 2005. Research with children: a critical review of the guidelines. Journal of Child Health Care, 9, 46-58.

PACE, C. S. \& ZAVATTINI, G. C. 2011. 'Adoption and attachment theory' the attachment models of adoptive mothers and the revision of attachment patterns of their late-adopted children. Child: Care, Health \& Development, 37, 82-88.

PAIGE-SMITH, A. \& RIX, J. 2006. Parents' perceptions and children's experiences of early intervention. Inclusive practice? Journal of Research in Special Educational Needs, 6, 92-98.

PIEK, J. P., DAWSON, L., SMITH, L. M. \& GASSON, N. 2008. The role of early fine and gross motor development on later motor and cognitive ability. Human Movement Science, 27, 668681.

REYNOLDS, D., NICOLSON, R. I. \& HAMBLY, H. 2003. Evaluation of an exercise-based treatment for children with reading difficulties. Dyslexia (10769242), 9, 48-71.

RICHARDSON, L. \& ADAMS ST PIERRE, E. 2008. Writing - A method of inquiry. In: DENZIN, N. K. \& LINCOLN, Y. S. (eds.) Collecting and interpreting qualitative materials. 3rd ed. CA: Sage.

SASSÉ, M. 2009. Smart start: How exercise can transform your child's life, Wollombi, NSW, Exisle Publishing.

SINGLETON, C. \& STUART, M. 2003. Measurement mischief: A critique of Reynolds, Nicolson and Hambly (2003). Dyslexia: An International Journal of Research and Practice, 9, 151160.

SNAPE, D. \& SPENCER, L. 2003. The foundations of qualitative research. In: RITCHIE, J. \& LEWIS, J. (eds.) Qualitative research practice. London: Sage Publications.

TAYLOR, M., HOUGHTON, S. \& CHAPMAN, E. 2004. Primitive reflexes and attentiondeficit/hyperactivity disorder: Developmental origins of classroom dysfunction. International Journal of Special Education, 19, 23-37.

TOMASELLO, N. M., MANNING, A. R. \& DULMUS, C. N. 2010. Family-centered early intervention for infants and toddlers with disabilities. Journal of Family Social Work, 13, 163172.

WILLIAMS, J. 2005. Learning from mothers: How myths, policies and practices affect the early detection of subtle developmental problems in children. $\mathrm{PhD}$, James Cook University.

WILLIAMS, J. \& HOLMES, C. A. 2004. Improving the early detection of children with subtle developmental problems. Journal of Child Health Care, 8, 34-46. 